\title{
Congenital hepatic fibrosis with novel mutations in PKD1 gene masquerading as early cryptogenic cirrhosis: a rare case report
}

\author{
Souradeep Dutta ${ }^{1}$ (B), Ankit Jain ${ }^{1}$, Reddy Abhinaya ${ }^{1}$, Bheemanathi Hanuman Srinivas² ${ }^{2}$ and \\ Vishnu Prasad Nelamangala Ramakrishnaiah ${ }^{1 *}$ (D)
}

\begin{abstract}
Background: Congenital hepatic fibrosis (CHF) is a rare disorder of the porto-biliary system occurring due to the defective remodeling of ductal architecture leading to progressive fibrosis of the portal tract. Though classically, CHF has been reported to be associated with autosomal recessive polycystic kidney disease (ARPKD), there have been only a few reports associating CHF with autosomal dominant polycystic kidney disease (ADPKD). Also, there is a lack of proper sequencing panels and gene database covering CHF-related genes in the medical literature. CHF often presents with features of portal hypertension without overt signs or symptoms of liver disease. However, often due to lack of awareness among radiologists and physicians, such cases might get labeled as early stage of cryptogenic cirrhosis.

Case presentation: Here, we report a 17-year-old boy who presented with a portal hypertensive bleed. Though initially an early phase of cirrhosis was suspected, no identifiable cause was found. Though he had grade IV esophageal varices, the liver function was absolutely normal with no signs of liver failure. This further leads to subsequent crosssectional imagings which lead to the diagnosis of CHF. Further genetic analysis revealed it to be a rare case of CHF associated with ADPKD, with some novel mutations in the PKD1 gene.

Conclusion: $\mathrm{CHF}$ is a rare disorder needing a high index of suspicion and awareness. The presence of classic radiological morphological features of left lobe hypertrophy and right lobe atrophy with the tell-tale histopathological findings, fibrous enlargement of the portal tract, and irregularly shaped proliferating bile ducts often clinches the diagnosis.
\end{abstract}

Keywords: Congenital hepatic fibrosis, Portal hypertension, Polycystic kidney disease, Case report

\section{Background}

Congenital hepatic fibrosis (CHF) is a rare congenital disease of the liver's porto-biliary system caused as a result of a faulty remodeling of the ductal plate architecture leading to progressive fibrosis of the portal tract [1]. Classically, CHF has been reported to be associated with autosomal recessive polycystic kidney disease (ARPKD); however, there is a lack of proper sequencing panels and

\footnotetext{
* Correspondence: vprasad285@gmail.com

${ }^{1}$ Division of GI \& HPB Surgery, Department of Surgery, Jawaharlal Institute of Postgraduate Medical Education and Research, Puducherry 605006, India Full list of author information is available at the end of the article
}

gene database covering CHF-related genes in the medical literature [2]. It generally presents with features of portal hypertension without any apparent signs or symptoms of liver disease. However, often due to lack of awareness among radiologists and physicians, such cases might get labeled as "idiopathic or cryptogenic early cirrhosis."

\section{Case presentation}

A 17-year-old boy presented to the surgical emergency with massive bouts of hematemesis. He gave a similar history of hematemesis episodes twice, 4 years back, which were conservatively managed, without any

\section{Springer Open}

(c) The Author(s). 2021 Open Access This article is licensed under a Creative Commons Attribution 4.0 International License, which permits use, sharing, adaptation, distribution and reproduction in any medium or format, as long as you give appropriate credit to the original author(s) and the source, provide a link to the Creative Commons licence, and indicate if changes were made. The images or other third party material in this article are included in the article's Creative Commons licence, unless indicated otherwise in a credit line to the material. If material is not included in the article's Creative Commons licence and your intended use is not permitted by statutory regulation or exceeds the permitted use, you will need to obtain permission directly from the copyright holder. To view a copy of this licence, visit http://creativecommons.org/licenses/by/4.0/. 
intervention. There was no history of alcohol abuse. His parents gave no history suggestive of poor developmental delay or neuropsychiatric abnormalities. At presentation, he was alert and conscious. On examination, he was severely pale, tachycardic (150 bpm), and hypotensive $(80 / 40 \mathrm{mmHg})$. Abdominal examination revealed massive splenomegaly reaching down to the umbilicus. There was no ascites, no dilated/prominent veins, or other stigmata of chronic liver disease. Laboratory parameters showed severe anemia ( $\mathrm{Hb} \mathrm{4.8),} \mathrm{leuco-}$ penia (TC WBC $2.8 \mathrm{G} / \mathrm{l})$, thrombocytopenia $(40,000 / \mathrm{dl}$ ), and normal liver function.

After initial resuscitation and hemodynamic stability, upper GI endoscopy was done, which revealed grade IV esophageal varices with no gastric varices. Band ligation was done in the same setting. He was further investigated to look for the cause of portal hypertension. An abdominal ultrasound showed multiple bilateral renal cysts with altered liver echoes, splenomegaly $(18 \mathrm{~cm})$, a patent portal vein of diameter $10 \mathrm{~mm}$ with hepatopetal flow, and high Acoustic Radiation Force Impulse (ARFI) values (1.7) suggestive of chronic liver disease. Wilson's disease, glycogen storage disorders, hemochromatosis, autoimmune hepatitis, viral hepatitis, and cystic fibrosis were ruled out with subsequent investigations. Due to the presence of grade IV varices with a very well- preserved liver function and no identifiable cause of liver disease, further cross-sectional imaging was planned to identify any non-cirrhotic pathology.

A contrast-enhanced computed tomography (CECT) showed dysmorphic liver (hypertrophic left lateral and medial segments and atrophic right lobe), splenomegaly, and multiple small bilateral renal cysts (Fig. 1a-c). With a high index of suspicion for CHF based on existing literature, a T2-weighted magnetic resonance imaging (MRI) was also done, which showed high periportal signal intensity (Fig. 1d). Thereafter, to decrease his dependence on endoscopy sessions, prevent further bleeding episodes, and to address the hypersplenism features, he was taken up for splenectomy and proximal splenorenal shunt (PSRS). He had an uneventful post-surgical recovery. A liver biopsy was taken intra-operatively which showed ductal plate malformation and periportal fibrosis suggestive of congenital hepatic fibrosis (Fig. 2). Due to the disease's inherited nature, a genetic evaluation was done. The genomic DNA was extracted from the peripheral blood and using targeted next-generation gene sequencing, seven genes commonly associated with fibropolycystic diseases of kidney and liver (PKHD1, PKD1, PKD2, MUC1, GANAB, UMOD, DZIP1L) were analyzed. Results showed two heterozygous missense mutations in the PKD 1 gene suggestive of autosomal

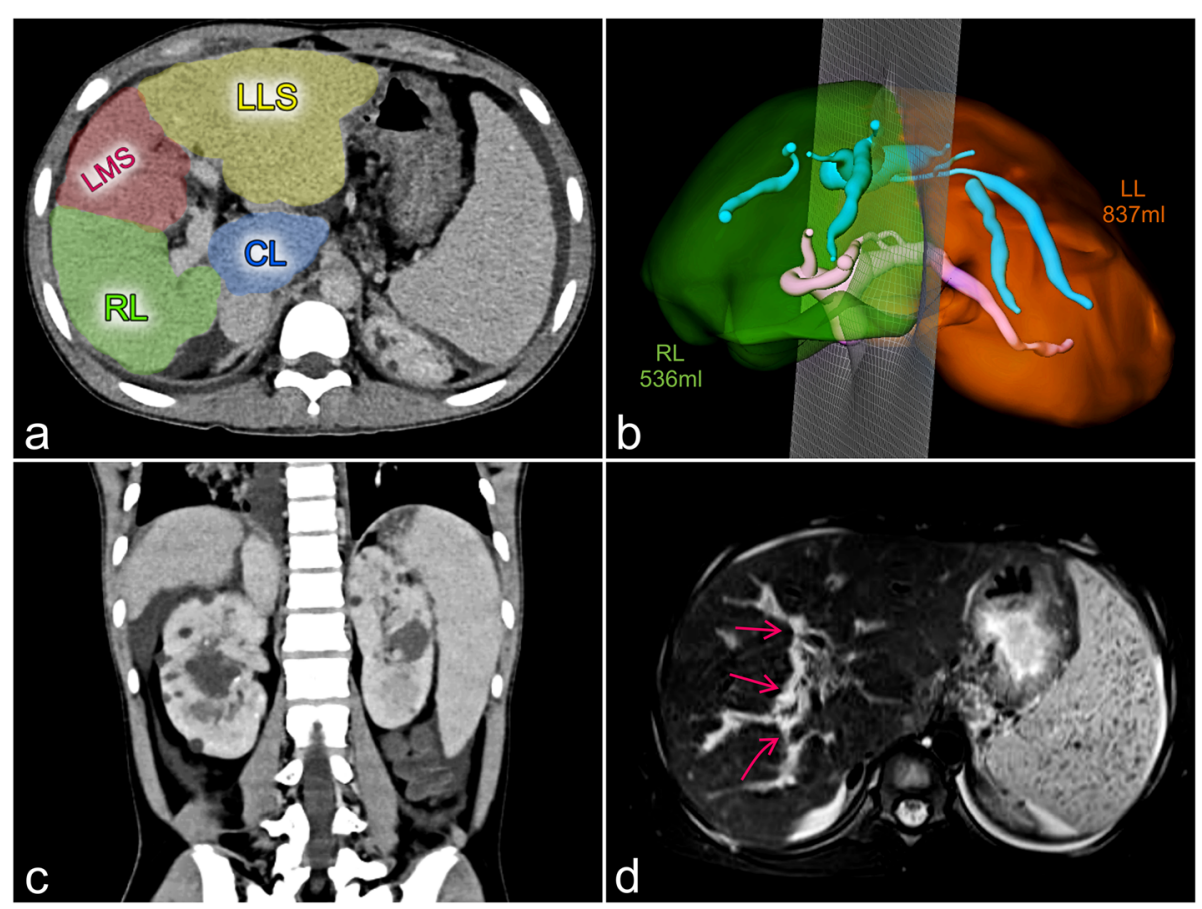

Fig. 1 a Contrast-enhanced computed tomography (CECT) portal phase (axial section at the level of portal vein bifurcation) showing hypertrophic left lateral (yellow) and medial (red) segments, hypertrophic caudate lobe (blue), and atrophic right lobe (green). LLS-left lateral segment, LMS—left medial segment, RL—right lobe, CL_caudate lobe. b Three-dimensional virtual liver segmentation showing hypertrophied left lobe (837cc) vs small right lobe (536cc). RL-right lobe, LL-left lobe. c Coronal section in CECT showing multiple cysts in bilateral kidneys. $\mathbf{d}$ T2-weighted magnetic resonance imaging showing high periportal signal intensities with widened portal tracts (red arrows). 


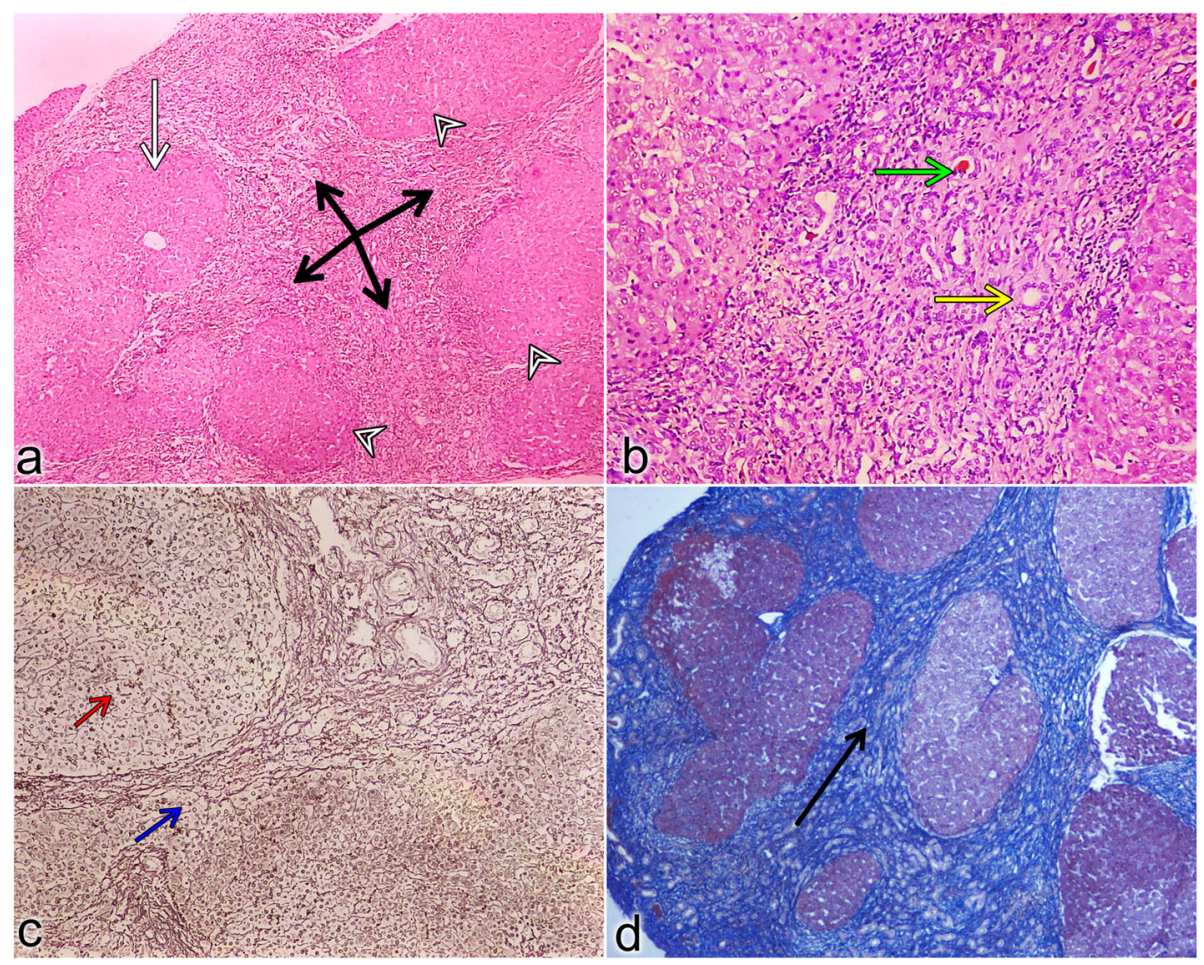

Fig. 2 Sections from the wedge biopsy of liver showing a loss of normal architecture with irregular bridging fibrosis (black arrows) separating the liver parenchyma into lobules (white arrow) and irregular nodules (white arrow heads) (H\&E, $\times 40)$. b Bile ductular proliferation (yellow arrow) and bile plugging (green arrow) $\left(H \& E_{1} \times 200\right)$. c Reticulin stain has highlighted the fibrosis (blue arrow) outlining a nodule and the nodule shows maintained reticulin framework (red arrow) (reticulin stain, $\times 100$ ). $\mathbf{d}$ Masson's trichrome stain has highlighted the irregular fibrosis (black arrow) between islands of liver parenchyma imparting a jigsaw-puzzle pattern (MT, $\times 40)$

dominant polycystic kidney disease (ADPKD). The genetic variations seen in the patient are summarized in Table 1. These mutations have been described in the PKD1 gene database panel as likely pathogenic but have not been reported in any case of CHF earlier. The patient's father though asymptomatic, was screened with an abdominal ultrasound, which showed bilateral multiple renal cysts, but the liver was morphologically normal. No other first or second-degree relatives could be clinically or genetically evaluated due to financial constraints.

\section{Discussion}

$\mathrm{CHF}$ is a rare progressive fibrotic process involving the liver that results from a malformation of the ductal plate. Though the existence of such a disease process was first described in 1856 [3], it was much later in 1960 and 1961 when the term "congenital hepatic fibrosis" came into existence with more elaborated clinical descriptions
$[4,5]$. A ductal plate is the embryological precursor of intrahepatic bile ducts and is formed by a cylindrical layer of epithelial cells that surrounds a branch of the portal vein [6]. Maturation arrest and the lack of remodeling of the ductal plate can occur resulting in the persistence of an increased number of immature embryological ductal structures, which stimulates excessive periportal fibrosis, giving rise to the various clinical manifestations [7].

Though CHF has been mostly associated with ARPKD, there have been a few reports associating CHF with ADPKD [8-11] like our present case, but the mutations described in this case are novel and have not been described for CHF previously. Other rare syndromic associations with $\mathrm{CHF}$ are with Joubert syndrome, Senior-Loken syndrome, $\mathrm{COACH}$ syndrome, and Cogan syndrome [7].

The clinical presentation and severity of symptoms in $\mathrm{CHF}$ are very variable. It usually presents in the

Table 1 The summary of the novel mutations in PKD1 gene in this patient with congenital hepatic fibrosis

\begin{tabular}{lllll}
\hline Gene & Exon location & Nucleotide change & Amino acid change & Zygosity \\
\hline PKD 1 & Exon 15 & C.6223C $>T$ & p.Arg2075Cys & Heterozygous \\
PKD 1 & Exon 11 & C.2534T>C & p.Leu845Ser & Heterogenous \\
\hline
\end{tabular}


childhood or early adulthood as one of the four broad types: portal hypertension, cholestatic, mixed, and latent [12]. Due to its rarity, if CHF diagnosis is not established during childhood, it can be easily missed or unrecognized in adult patients who present with an upper GI bleed, and they often get labeled as early cirrhotics or non-cirrhotic portal hypertension.

Diverse radiological modalities are present to detect this disease. Ultrasonography with a splenoportal Doppler is usually the first investigation for such a patient with portal hypertension. Although challenging experienced radiologists can pick up the morphological changes of liver lobes, biliary dilatations and cysts, portal vein changes, and cystic changes in kidneys on ultrasonography. Cross-sectional imaging modalities like CECT or MRI can show changes in the gross morphology of the liver with accurate volume measurements. T2-weighted MRI would also show high signal intensity in the periportal regions suggesting periportal fibrosis and proliferating small biliary ductules [13]. A high index of suspicion for CHF should be there in patients with imaging features like hypertrophy of the left lateral segment and caudate lobe, normal or hypertrophic left medial segment, atrophic right lobe, presence of splenomegaly, and other portal hypertensive features and cystic renal abnormalities [14]. In CHF, the left medial segment is usually normal or enlarged, while in liver parenchymal cirrhosis, atrophy of the medial segment is seen [15]. There might be other associated features of ductal plate malformation such as biliary hamartomas or Caroli's disease, cavernoma formation, or benign regenerative nodules, but their presence is not mandatory for the diagnosis of CHF.

Although a liver biopsy clinches the diagnosis of CHF unequivocally, findings might be often mistaken for a cirrhotic liver. Widened fibrous bands in the portal tract with an increased number of irregularly shaped proliferating bile ducts, lined by normal cuboidal epithelium, is the hallmark of CHF. Hepatic lobules with hepatocyte morphology usually stay normal, unlike a cirrhotic liver [7]. Role of genetic evaluation is not for the diagnosis, but in the fact that CHF is a rare inherited disease associated with several genetic syndromes which might have other systemic involvement later in the course and therefore, influence the treatment strategies as a whole. Also, like in this case, the presence of an autosomal dominant mutation can help us do genetic counseling of the patient and the family members.

There is no treatment modality shown till date, to stop or reverse the fibrotic pathological process in congenital hepatic fibrosis. Treatment mainly involves managing the complications, like portal hypertension, as in this case. Though endoscopic therapies such as band ligation or glue injection are the mainstay for an acute bleeding episode or primary and secondary prophylactic management of esophageal and gastric varices, surgical portosystemic shunts provide long-term relief and decrease the dependence on repeated endoscopy sessions $[2,16]$. For patients who present at later stages with the signs of liver failure or extensive hepatic fibrosis, liver transplantation remains the only treatment option [17].

\section{Conclusion}

$\mathrm{CHF}$ is a rare disorder needing a high index of suspicion and awareness. Despite characteristic morphologic features in cross-sectional imaging or biopsy, a multidisciplinary approach by clinicians, pathologists, and radiologists is crucial for an accurate diagnosis. The management is directed toward supportive treatment and relieving complications, including interventions for portal hypertension.

\section{Abbreviations}

ADPKD: Autosomal dominant polycystic kidney disease; ARFI: Acoustic radiation force impulse; ARPKD: Autosomal recessive polycystic kidney disease; CECT: Contrast-enhanced computed tomography; CHF: Congenital hepatic fibrosis; MRI: Magnetic resonance imaging; PSRS: Proximal splenorenal shunt

\section{Acknowledgements}

Not applicable

\section{Authors' contributions}

Concept and design: SD, VPNR. Data acquisition and analysis, manuscript preparation: SD, BHS. Critical revision and finalizing of the manuscript: SD, AJ, RA, VPNR. All authors contributed to the conceptualization and design of the case report. All authors have read and approved the final manuscript.

\section{Funding}

The authors received no funding for this study.

Availability of data and materials

All data generated or analyzed during this study are included in this published article.

\section{Declarations}

Ethics approval and consent to participate

The study was approved by the Institutional Ethics Committee of Jawaharlal Institute of Postgraduate Medical Education and Research, Puducherry, India (JIP/IEC/2021/168). Written informed consent to participate was obtained from the patient's father.

\section{Consent for publication}

Written informed consent was obtained from the patient's father for publication of this case report and the accompanying images.

\section{Competing interests}

The authors declare that they have no competing interests.

\section{Author details}

${ }^{1}$ Division of Gl \& HPB Surgery, Department of Surgery, Jawaharlal Institute of Postgraduate Medical Education and Research, Puducherry 605006, India.

${ }^{2}$ Department of Pathology, Jawaharlal Institute of Postgraduate Medical Education and Research, Puducherry 605006, India.

Received: 13 January 2021 Accepted: 22 June 2021

Published online: 01 July 2021

\section{References}

1. Wen J (2011) Congenital hepatic fibrosis in autosomal recessive polycystic kidney disease. Clin Transl Sci 4(6):460-465. https://doi.org/10.1111/j.17528062.2011.00306.x 
2. Zhu B, Du Z, Wang Z, Li Y, Zhang J, Zhu H (2020) Congenital hepatic fibrosis in children and adults: clinical manifestations, management, and outcome - case series and literature review. Gastroenterol Res Pract 2020:1-9

3. BRISTOWE JS (1856) Cystic disease of the liver associated with similar disease of the kidneys. Trans Pathol Soc Lond 7:229-235

4. Dobbs RH (1960) Congenital hepatic fibrosis with portal hypertension. Proc R Soc Med 53:327-328

5. Kerr DN, Harrison CV, Sherlock S, Walker RM (1961) Congenital hepatic fibrosis. Q J Med 30:91-117

6. Strazzabosco M, Fabris $L$ (2012) Development of the bile ducts: essentials for the clinical hepatologist. J Hepatol 56(5):1159-1170. https://doi.org/10.1 016/j.jhep.2011.09.022

7. Shorbagi A (2010) Experience of a single center with congenital hepatic fibrosis: a review of the literature. WJG. 16(6):683-690. https://doi.org/10.374 8/wjg.v16.6.683

8. Cobben JM, Breuning MH, Schoots C, ten Kate LP, Zerres K (1990) Congenital hepatic fibrosis in autosomal-dominant polycystic kidney disease. Kidney Int 38(5):880-885. https://doi.org/10.1038/ki.1990.286

9. Lipschitz B, Berdon WE, Defelice AR, Levy J (1993) Association of congenital hepatic fibrosis with autosomal dominant polycystic kidney disease. Report of a family with review of literature. Pediatr Radiol 23(2):131-133. https://doi. org/10.1007/BF02012406

10. Matsuda O, Ideura T, Shinoda T, Shiigai T, Takeuchi H, Chen WC et al (1990) Polycystic kidney of autosomal dominant inheritance, polycystic liver and congenital hepatic fibrosis in a single kindred. Am J Nephrol 10(3):237-241. https://doi.org/10.1159/000168088

11. Lee Fl, Paes AR (1985) Congenital hepatic fibrosis and adult-type autosomal dominant polycystic kidney disease in a child. Postgrad Med J 61(717):641642. https://doi.org/10.1136/pgmj.61.717.641

12. Di Bisceglie AM, Befeler AS (2007) Schiff's Diseases of the Liver, 10th edn. Lippincott Williams \& Wilkins, Philadelphia, pp 1231-1251

13. Akhan $\mathrm{O}$, Karaosmanoğlu AD, Ergen B (2007) Imaging findings in congenital hepatic fibrosis. Eur J Radiol 61(1):18-24. https://doi.org/10.1016/j.ejrad.2 006.11 .007

14. Brancatelli G, Federle MP, Vilgrain V, Vullierme M-P, Marin D, Lagalla R (2005) Fibropolycystic liver disease: $C T$ and MR imaging findings. RadioGraphics. 25(3):659-670. https://doi.org/10.1148/rg.253045114

15. Zeitoun D, Brancatelli G, Colombat M, Federle MP, Valla D, Wu T, Degott C, Vilgrain V (2004) Congenital hepatic fibrosis: CT findings in 18 adults. Radiology. 231(1):109-116. https://doi.org/10.1148/radiol.2311030108

16. Zhang J-S, Cheng W, Li L (2017) Laparoscopic distal splenoadrenal shunt for the treatment of portal hypertension in children with congenital hepatic fibrosis: A case report. Medicine. 96(3):e5843. https://doi.org/10.1097/MD. 0000000000005843

17. Geramizadeh B, Keramati P, Bahador A, Salahi H, Nikeghbalian S, Dehghani SM, Malek-Hosseini SA (2010) Congenital hepatic fibrosis and need for liver transplantation. Int J Organ Transplant Med 1(2):98-100

\section{Publisher's Note}

Springer Nature remains neutral with regard to jurisdictional claims in published maps and institutional affiliations.

\section{Submit your manuscript to a SpringerOpen ${ }^{\circ}$ journal and benefit from:}

- Convenient online submission

- Rigorous peer review

- Open access: articles freely available online

- High visibility within the field

- Retaining the copyright to your article

Submit your next manuscript at $\boldsymbol{\nabla}$ springeropen.com 